\title{
Effectiveness of Structured Teaching Program on Knowledge and Practice of Adult Basic Life Support Among Staff Nurses
}

\author{
Vinil Upendrababu ${ }^{1}$, Dipeesh Kunjumon ${ }^{2}$ \\ ${ }^{1}$ Department of Nursing, College of Health Sciences, Wollega University, Nekemte, Ethiopia \\ ${ }^{2}$ The Edith Cavell Campus, Peterborough, United Kingdom
}

Email address:

vinilupendrababu@gmail.com (V. Upendrababu), dipeesh.kunjumon@nhs.net (D. Kunjumon)

\section{To cite this article:}

Vinil Upendrababu, Dipeesh Kunjumon. Effectiveness of Structured Teaching Program on Knowledge and Practice of Adult Basic Life Support Among Staff Nurses. American Journal of Nursing Science. Vol. 7, No. 3, 2018, pp. 100-105. doi: 10.11648/j.ajns.20180703.13

Received: April 22, 2018; Accepted: May 10, 2018; Published: May 28, 2018

\begin{abstract}
According to sudden cardiac arrest associations, It has been estimated that SCD claims more than 7,000,000 lives per year worldwide [1]. It is proved that Effective basic life support giving soon after cardiac arrest doubles the chance of survival [2]. Basic life support by nurses who are usually first on the scene provides the best opportunity to minimize the time to initiate cardio pulmonary resuscitation. Hence the main objective of the study was to find out the knowledge and practice of adult basic life support among staff nurses and to evaluate the effectiveness of structured teaching program on knowledge and practice regarding adult basic life support. 30 staff nurses from Upasana hospital, kollam were selected as the samples by using non probability convenient sampling technique. Pre experimental one group pretest posttest study design was employed to collect the data from staff nurses before and after the implementation of structured teaching program. The study was statistically significant at.001 level. The total mean post- test knowledge score (26.80) was significantly higher than the mean pretest score (12.36). The total mean posttest practice score (26.80) of adult basic life support was significantly higher than the mean pretest practice score regarding adult basic life support. Therefore, the study proved that the structured teaching program was an effective technique in imparting knowledge and practice regarding adult basic life support among staff nurses.
\end{abstract}

Keywords: Effectiveness, Knowledge, Practice, Adult Basic Life Support, Staff Nurses, Structured Teaching Program

\section{Introduction}

Cardio vascular diseases are one of the leading causes of death around the world [2]. Sudden cardiac death is often the first expression of CAD and is responsible for approximately $80 \%$ of deaths from CAD [3]. Also, it is one of the most common unfortunate incidents that may occur in and out of the health facilities [4]. Cardio pulmonary arrest results in death within minutes if not immediately corrected. The main organ to suffer oxygen starvation is the brain, which sustains irreversible damage after about four minutes. The American Heart Association estimated that in the world among the overall population the incidence of death due to cardiac arrest varies between 0.2 to 0.4 percentages per year. WHO estimates that the annual incidence of cardiac arrest is 0.55 per 1000 populations.

Sudden Cardiac Deaths account for more than $40-45 \%$ of cardiovascular deaths in India. In India the annual incidence of Sudden Cardiac death accounts for 0.55 per 1000 population as per the Wockhardt hospitals guide to wellness, 2010.

When cardiac or respiratory arrest occurs prompt action is necessary to provide oxygen to the brain and heart until advanced cardiac life support can restore normal cardiac and respiratory function. These emergencies can be easily managed by knowledge and practice of resuscitation skills. Over time, resuscitation skills have evolved into a proper protocol, which involves Cardiopul-monary Resuscitation (CPR) commonly known as Basic Life Support (BLS)[5].

Basic life support includes maintaining air way and supporting breathing and circulation with an AED. It comprises recognition of signs of sudden cardiac arrest, heart attack, stroke, obstruction of airway by a foreign body, circulation, opening airway, breathing, managing chocking 
victim [1].

Studies show that survival rates from cardiac arrest remain poor despite the development of both cardiopulmonary resuscitation and electrical defibrillation as treatment modalities over the past 50 years.

Nurses are found to be the primary health care providers in emergency hospital settings. Prompt actions by nurses who are usually on the scene provide the best opportunity to minimize time to initiate cardio pulmonary cerebral resuscitation [6]. All nurses need to be trained in basic life support [7].

In a study conducted by Chandrasekaran S. on Awareness of Basic Life Support (BLS) among students, doctors and nurses was very poor and recommended that their knowledge and practice to be improved [8].

A quasiexperimental study conducted by Daisey C. (2009) to assess the effectiveness of structured teaching program on knowledge and skill of cardiopulmonary resuscitation among staff nurses working in selected hospitals found out that the knowledge and skill of staff nurses regarding cardio pulmonary resuscitation are very poor and the study report that after the administration of structured teaching program the knowledge and skill of staff nurses are improved [9].

It is quite evident that Survival after cardiac arrest has been improved by extensive education of health care providers and by the use of semiautomatic defibrillators. Hence the researcher found that basic life support training to staff nurses is an effective strategy to reduce the mortality and morbidity resulting from sudden cardiac arrest.

\subsection{Statement of the Problem}

The statement of the problem for the present study was

"Effectiveness of structured teaching program on knowledge and practice of adult basic life support among staff nurses working in Upasana Hospital, Kollam.”

\subsection{Objective}

The objectives of the study were

1. To evaluate the effectiveness of structured teaching program on knowledge regarding adult basic life support among staff nurses.

2. To evaluate the effectiveness of structured teaching program on practice regarding adult basic life support among staff nurses.

3. To find out the association between the pretest knowledge score and the selected demographic variables such as age, sex, education, years of experience, clinical area of work.

4. To find out the association between the pretest practice score and the selected demographic variables such as age, sex, education, years of experience, clinical area of work.

\subsection{Hypotheses}

$\mathrm{H}_{1}$ : The mean posttest knowledge score will be significantly higher than that of the mean pretest score.
$\mathrm{H}_{2}$ : The mean posttest practice score will be significantly higher than that of the mean pretest score.

\section{Method}

\subsection{Design and Setting}

The research approach adopted for the study was pre experimental and the research design was of one group pretest-posttest design. The study was conducted in Upasana hospital, kollam.

\subsection{Sample Size and Sampling Technique}

30 staff nurses working in Upasana hospital, kollam, were selected by non probability convenient sampling technique.

\subsection{Assesment Tools}

1. Baseline proforma which includes the sociodemographic data like age, sex, education, years of experience and clinical area of work.

2. Structured questionnaire for assessing knowledge regarding adult basic life support.

3. Observation checklist to assess practice regarding adult basic life support. It consists of 20 items divided in to 8 parts.

\subsection{Duration of the Study}

Duration of study was six weeks. The study was conducted from 01-08-2016.

\subsection{Validity and Reliability}

The reliability of the structured questionnaire was checked by split half method. The reliability of the observation checklist was assessed by interrator method. The tool was administered among three staff nurses working in UpasanaHospital. Using Karl Pearson's formula for correlation coefficient

$\mathrm{r}=0.76$ for structured questionnaire and $\mathrm{r}=0.72$ for observation checklist.

Using Spearman Brown's Prophecy formula:

$\mathrm{R}=0.8$ for structured questionnaire and $\mathrm{R}=0.86$ for the observation checklist. The tool was found to be reliable.

\subsection{Data Collection Procedure}

After obtaining consent from the sample, demographic data were collected by semistructured questionnaire; their knowledge level was assessed by structured questionnaire and practice by an observation checklist. Structured teaching program was provided on the same day of pretest and posttest was assessed with the same tool on the seventh day after structured teaching program.

\section{Result}

The data thus obtained were analyzed and presented under the following sections. 


\subsection{Demographic Data}

1. Among the total sample, $43 \%$ belongsto the age group of $21-23$ years and $47 \%$ in the age group of $24-26$ and only $10 \%$ in the age group of $27-29$.

2. Majorities $(90 \%)$ of the sample were females and only $10 \%$ of the samples were male.

3. Educational qualifications of $57 \%$ of staff nurses were
GNM and the remaining were graduates.

4. Among 30 samples majority $(73 \%)$ of the staff have the clinical experience of 1-3 years and $20 \%$ staff had the experience of 4-6 years and 7\% had the experience of 7-9 years.

5. Among 30 samples $38 \%$ were in ICU, $13 \%$ were in $\mathrm{CCU}, 33 \%$ were in general ward, $13 \%$ were in OT and $3 \%$ were in OPD.

\subsection{Pretest Knowledge Score Regarding Adult Basic Life Support}

Table 1. Pretest knowledge score of staff nurses regarding adult basic life support.

\begin{tabular}{|c|c|c|c|c|c|c|c|c|}
\hline \multirow{2}{*}{ Area of knowledge } & \multicolumn{2}{|c|}{ Excellent } & \multicolumn{2}{|c|}{ Good } & \multicolumn{2}{|c|}{ Average } & \multicolumn{2}{|c|}{ Poor } \\
\hline & No. & $\%$ & No. & $\%$ & No. & $\%$ & No. & $\%$ \\
\hline Anatomy and physiology & 0 & 0 & 5 & 16.7 & 22 & 73.3 & 3 & 10 \\
\hline Basic life support & 0 & 0 & 1 & 3.3 & 10 & 33.3 & 19 & 63.33 \\
\hline Assessment & 0 & 0 & 14 & 46.7 & 11 & 36.7 & 5 & 16.7 \\
\hline Circulation & 0 & 0 & 4 & 13.3 & 14 & 46.7 & 12 & 40 \\
\hline Airway & 0 & 0 & 0 & 0 & 2 & 6.7 & 28 & 93.3 \\
\hline Total & & 0 & & 0 & & 67 & & 33 \\
\hline
\end{tabular}

1. Only $16.7 \%$ staff had good knowledge score regarding the anatomy and physiology of respiratory system, cardiovascular system and cerebrum, where as $73.3 \%$ staff had average knowledge, $10 \%$ staff had poor knowledge.

2. About the basic life support only 3.3\% had good knowledge. In contrast $63.33 \%$ staff had poor knowledge and $33.3 \%$ staff had average knowledge.

3. Only $46.7 \%$ of the sample had good knowledge score in preliminary assessment during basic life support. In contrast $36.7 \%$ staff had average knowledge and $16.7 \%$ staff had poor knowledge.

4. Nearly half of the sample had average knowledge regarding chest compression, where as $40 \%$ of the staff had poor knowledge and only $13.3 \%$ staff had good knowledge.

5. Majority of the sample had poor knowledge regarding opening the airway, where as $6.7 \%$ staff had average knowledge and nobody had good knowledge.

6. $56.7 \%$ staff showed poor knowledge about breathing. In contrast $26.7 \%$ staff had average knowledge and $16.7 \%$ staff had good knowledge.

\subsection{Pretest Practice Score Regarding Adult Basic Life Support}

Table 2. Pretest practice score of staff nurses regarding adult basic life support.

\begin{tabular}{|c|c|c|c|c|c|c|c|c|}
\hline \multirow{2}{*}{ Area of knowledge } & \multicolumn{2}{|c|}{ Excellent } & \multicolumn{2}{|c|}{ Good } & \multicolumn{2}{|c|}{ Average } & \multicolumn{2}{|c|}{ Poor } \\
\hline & No. & $\%$ & No. & $\%$ & No. & $\%$ & No. & $\%$ \\
\hline Assessment & 0 & 0 & 1 & 3.3 & 0 & 0 & 29 & 96.7 \\
\hline Call for help & 0 & 0 & 7 & 23.3 & 0 & 0 & 23 & 76.7 \\
\hline Chest compression & 0 & 0 & 0 & 0 & 5 & 16.7 & 25 & 83.3 \\
\hline Airway & 0 & 0 & 6 & 20 & 0 & 0 & 24 & 80 \\
\hline Breathing & 0 & 0 & 0 & 0 & 1 & 3.3 & 29 & 96.7 \\
\hline
\end{tabular}

1. Majority (96.7\%) of the sample failed to assess the client before giving basic life support, whereas only $3.3 \%$ showed good performance.

2. Only $23.3 \%$ attempted to call for a help before starting chest compression, whereas the rest of the sample showed poor performance.

3. About the chest compression, 83.3\% sample demonstrated wrong technique, whereas the rest of the sample showed average performance, nobody showed good performance.

4. For opening an airway, $80 \%$ staff demonstrated poor practice. In contrast, the rest of the sample showed good performance.

5. $96.7 \%$ staff failed to give breath after opening an airway, whereas the rest of the sample showed average performance, nobody showed good performance.

6. For reassessing the client after CPR 93.3\% staff showed poor practice. In contrast an equal distribution of $3.3 \%$ staff showed average as well as good performance.

7. Over all $70 \%$ staff showed poor practice in adult basic life support, whereas the rest of the staff showed average performance in practicing adult basic life support. 


\subsection{Effectiveness of Structured Teaching Program on Knowledge Regarding Adult Basic Life Support}

Table 3. Comparison of pretest and posttest knowledge scores.

\begin{tabular}{lllll}
\hline \multirow{2}{*}{ Knowledge } & Pre & \multicolumn{3}{c}{ Post } \\
\cline { 2 - 5 } & Frequency & Percent & Frequency & Percent \\
\hline Poor & 10 & 33 & 0 & 0 \\
Average & 20 & 67 & 0 & 0 \\
Good & 0 & 0 & 1 & 3 \\
Excellent & 0 & 0 & 29 & 97 \\
Total & 30 & 100 & 30 & 100 \\
\hline
\end{tabular}

Table 4. Significance of difference between pretest knowledge and posttest knowledge scores.

\begin{tabular}{lllllll}
\hline Knowledge & & $\mathbf{N}$ & Mean & Sd & t & P \\
\hline \multirow{2}{*}{ Anatomy and physiology } & Pre & 30 & 3.6 & 0.9 & 7.788 & 0.001 \\
& post & 30 & 4.9 & 0.3 & & \\
Basic life support & Pre & 30 & 2.3 & 0.9 & 15.314 & 0.001 \\
& post & 30 & 5.7 & 0.5 & & \\
Assessment & Pre & 30 & 1.3 & 0.8 & 4.589 & 0.001 \\
& post & 30 & 2.0 & 0.2 & & \\
Circulation & Pre & 30 & 3.5 & 2.3 & 10.028 & 0.001 \\
& post & 30 & 7.4 & 0.8 & & \\
Airway & Pre & 30 & 1.2 & 1.2 & 10.727 & 0.001 \\
& post & 30 & 5.2 & 1.8 & & \\
Breathing & Pre & 30 & 0.6 & 0.8 & 5.012 & 0.001 \\
& post & 30 & 1.4 & 0.6 & & \\
Total & Pre & 30 & 12.30 & 3.54 & 19.572 & 0.001 \\
\hline & post & 30 & 26.80 & 1.9 & & \\
\hline
\end{tabular}

$\mathrm{n}=30$

The structured teaching program had significantly increased the knowledge regarding adult basic life support.

1. In total knowledge score, the mean score was increased from 12.30 (pretest) to 26.80 (posttest), which was statistically significant $(\mathrm{p}=0.001)$

2. There was a significant increase in knowledge regarding anatomy and physiology of respiratory system, cardiovascular system, cerebrum after giving structured teaching program (mean score in pretest was 3.6 and in posttest 4.9$)$. $(\mathrm{p}=0.001)$.

3. The knowledge about basic life support was dramatically increased from the mean score 2.3 to 5.7 in posttest. ( $\mathrm{p}=0.001)$.

4. Regarding preliminary assessment the post mean score (2.0) increased from pretest mean score (1.3). $(\mathrm{p}=0.001)$.

5. In the posttest there was increased mean score (7.4) from pretest score (3.5) regarding knowledge of circulation. $(\mathrm{p}=0.001)$.

6. The knowledge about opening an airway was increased, the posttest score was 5.2 and pretest score was 1.2. $(p=0.001)$.

7. After administration of structured teaching program the knowledge score on breathing increased from 0.6 to 1.4 $(\mathrm{p}=0.001)$.

\subsection{Effectiveness of Structured Teaching Program on Practice Regarding Adult Basic Life Support}

Table 5. Pretest posttest comparison of practice.

\begin{tabular}{lllll}
\hline \multirow{2}{*}{ Practice } & Pre & \multicolumn{3}{c}{ Post } \\
\cline { 2 - 5 } & Frequency & Percent & Frequency & Percent \\
\hline Poor & 21 & 70 & 0 & 0 \\
Average & 9 & 30 & 0 & 0 \\
Good & 0 & 0 & 4 & 13.3 \\
Excellent & 0 & 0 & 26 & 86.7 \\
Total & 30 & 100 & 30 & 100 \\
\hline $\mathrm{n}=30$ & & & &
\end{tabular}

Table 6. Significance of difference between pretest practice and posttest practice scores.

\begin{tabular}{lllllll}
\hline Practice & & N & Mean & SD & t & p \\
\hline \multirow{2}{*}{ ASSESSMENT } & Pre & 30 & 0.379 & 0.677 & \multirow{2}{*}{15.362} & 0.001 \\
& post & 30 & 2.586 & 0.501 & & \\
CALL FOR HELP & Pre & 30 & 0.241 & 0.435 & 7.294 & 0.001 \\
& post & 30 & 0.897 & 0.31 & & \\
CHEST COMPRESSION & Pre & 30 & 2.172 & 1.56 & 24.100 & 0.001 \\
& post & 30 & 9.414 & 0.867 & & \\
AIRWAY & Pre & 30 & 0.2 & 0.407 & \multirow{2}{*}{7.167} & 0.001 \\
& post & 30 & 0.9 & 0.305 & & \\
BREATHING & Pre & 30 & 0.3 & 0.535 & \multirow{2}{*}{14.366} & 0.001 \\
& post & 30 & 2.6 & 0.77 & & \\
REASSESSMENT & Pre & 30 & 0.1 & 0.403 & \multirow{2}{*}{12.453} & 0.001 \\
& post & 30 & 1.733 & 0.583 & & \multirow{2}{*}{ TOTAL } \\
& Pre & 30 & 3.40 & 1.933 & \multirow{2}{*}{39.415} & 0.001 \\
& post & 30 & 18.40 & 1.354 & & 0.001 \\
\hline
\end{tabular}

$\mathrm{n}=30$

1. The pretest practice mean score was increased from 3.40 (pretest) to 18.40 (posttest), which was statistically significant $(\mathrm{p}=0.001)$.

2. There was a significant increase in practice regarding preliminary assessment after giving structured teaching program (mean score in pretest was 0.379 and in posttest 2.586, $(\mathrm{p}=0.001)$.

3. The practice of calling for a help before starting chest compression was dramatically increased from the mean score 0.241 to 0.897 ( $\mathrm{p}=0.001)$.

4. Regarding chest compression, theposttest mean score (9.414) is increased from pretest mean score (2.172). $(\mathrm{p}=0.001)$.

5. In the posttest, there was an increase in mean score from 0.2 to 0.9 .

6. The practice about giving breath to a victim was significantly improved from 0.3 to $2.6(\mathrm{p}=0.001)$.

7. Regarding the practice of reassessing the client after giving CPR, the score increased from.1 to 1.733 $(\mathrm{p}=0.001)$.

\subsection{Influence of Socio-Demographic Variables on Knowledge Score}

The influences of socio demographic variables on knowledge were tested by Chi square test. The variables tested were age, sex, education, and years of experience and clinical area of work. 
It was found that age, sex, education, years of experience and clinical area of work had no influence on knowledge of adult basic life support.

\subsection{Influence of Socio-Demographic Variables on Practice Score}

The influences of socio demographic variables on practice were tested by Chi square test. The variables tested were age, sex, and education, year of experience and clinical area of work.

1. It was observed that there was no association between age, sex, clinical area and years of experience and practice with regard to adult basic life support, whereas there was an association found between education and practice of adult basic life support. $\chi^{2}=6.212 ; \mathrm{df}=1 ; \mathrm{p}=0.013$

\section{Discussion}

Cardiac arrests and other life-threatening emer-gencies are crucial public health issues, where fast recognition and a skilled response can prevent potentially devastating outcomes [11].

In the study titled "Basic life support knowledge of undergraduate nursing and chiropractic students" conducted by Patricia Josipovic et al. (2009) found that students from both disciplines had significant gaps in knowledge of $\mathrm{CPR} / \mathrm{BLS}$. In the present study also the investigator found that there was a significant gap in the knowledge of staff nurses working in hospital setting [10].

It was evident from a prospective study that the chest compression rates during cardiopulmonary resuscitation are suboptimal (Benjamin s 2010). In the present study also the investigator found that the nurses are not having a good practice of adult basic life support.

A quasi experimental study to assess the effectiveness of structured teaching program on knowledge and skill of cardiopulmonary resuscitation among staff nurses working in a selected hospital, Hassan, Karnataka concluded that the knowledge and skills of the experimental group were significantly improved after the implementation of structured teaching program. Results of the study shows that the pretest knowledge score of this study was $37.3 \%$ which indicates staff nurses were having the average performance. Moreover, posttest knowledge and practice score became $80 \%$. In addition, it was show that there was an association found between age and skill, and knowledge about CPR. In this study also the investigator found that the knowledge and practice level was below average level in the pretest and in the posttest there was significant increase in knowledge and practice level and the staff shows excellent practice in the post practice test. There was no increase in knowledge with age, sex, education, year of experience and clinical area of work. The study was statistically significant at.001 level. The total mean posttest knowledge score (26.80) was significantly higher than the mean pre test score (12.36). The total mean posttest practice score (26.80) was significantly higher than the mean pretest practice score and it was also proved that there was no association of knowledge score and practice score with selected variables like age, sex, education, years of experience and clinical area of work.

Similar findings were reported by Adedamola Olutoyin Onyeaso also, and the findings revealed that the level of pretraining knowledge was $8.9 \%$ compared to post training knowledge of $88.6 \%$. The knowledge difference between pre and post training in CPR was statistically significant $(\mathrm{p}<0.05)$ [12]. This study also significant at 0.001 level. The mean posttest knowledge score was 26.80 which was significantly higher than the mean pretest knowledge score, which was 12.36 .

\section{Conclusion}

Based on the findings of the study, the investigator reached the conclusion that most of the staff nurses don't have adequate knowledge and majority of them had shown improper techniques of latest adult basic life support sequence before the implementation of structured teaching program. About the chest compression and opening airway, majority of them had shown very poor performances.

However, After the implementation of structured teaching program the knowledge and practice of adult basic life support among staff nurses had improved drastically, which was evident from the post knowledge as well as post practice score. Hence the first scientific hypothesis was accepted. Hence it was concluded that the structured teaching programme is an effective teaching strategy to improve the knowledge as well as practice of the staff nurse.

Also, it was more clear from the result that there was no significant association beween pretest knowledge and the selected demographic variables like age, sex, education, years of experience and clinical area of work. Similarly pretest practice score also failed to show significant association with the selected demographic variables such as age, sex, years of experience and clinical areas of work. In contrast pretest practice score had an positive association with educational level of staff nurses regarding adult basic life support. Hence the second scientific hypothesis is rejected.

\section{References}

[1] American Heart Association 2005 international consensus on CPR and ECC science with treatment recommendations. 2015.

[2] AHA. Heart disease and stroke statistics-2015 update: a report from the American Heart Association.

[3] Lewis et al. Medical surgical nursing, Assessment and management of clinical problems, Elseviers. 2009. 1845-1849.

[4] Shultz JJ, Lurie KG. Variations in cardiopulmonary resuscitation techniques: past, present and future. Can J Cardiol 1995; 11: 873-880.

[5] ZAHEER H. and HAQUE Z.: Awareness about BLS (CPR) among medical students: Status and requirements. J. P. M. A., 59 (1): 57-9, 2009. 
[6] Hamilton R. Nurses' knowledge and skill retention following cardiopulmonary resuscitation training: a review of the literature. Journal of advanced nursing. 2005, (51) 288-297.

[7] Polaski L. Arlene, Suzanne. Luckmann's core principles and practice of medical surgical nursing. Elseviers publication.

[8] Chandrasekaran S. et al. Awareness of basic life support among medical, dental, nursing students and doctors. Indian journal of anaesthesiology. 2010, (54) 121-126.

[9] Polaski L. Arlene, Suzanne. Luckmann's core principles and practice of medical surgical nursing. Elseviers publication.
[10] Patricia Josipovic. Research paper. Australian journal of advanced nursing. 2010, (26).

[11] LAMI M., NAIR P. and GADHVI K.: Improving basic life support training for medical students. Adv. Med. Educ. Pract., 7: 241-2, 2016.

[12] Adedamola Olutoyin Onyeaso. Knowledge of Cardiopulmonary Resuscitation among Some Secondary School Students in Nigeria. Journal of Education and Practice. 2014; 5:180-183. 